\title{
A Micro Gas Turbine for UK Domestic Combined Heat and Power
}

A Clay**, and GD Tansley

School of Engineering and Applied Science, Aston University, Birmingham, United Kingdom

\begin{abstract}
:
Various micro radial compressor configurations were investigated using 1D meanline and CFD techniques for use in a Micro Gas Turbine (MGT) Domestic Combined Heat and Power (DCHP) application. Blade backsweep, shaft speed, and blade height were varied at a constant pressure ratio. Shaft speeds were limited to 220,000 $\mathrm{rev} / \mathrm{min}$, to enable the use of a turbocharger bearing platform.

Off-design compressor performance was established and used to determine the MGT performance envelope; this in turn was used to assess potential cost and environmental savings in a heat-led DCHP operating scenario within the target market of a detached family home.
\end{abstract}

A low target stage pressure ratio provided an opportunity to reduce diffusion within the impeller. Critically for DCHP, this produced very regular flow which improved impeller performance for a wider operating envelope.

The best performing impeller was a low speed, 170,000 rev/min, low backsweep, $15^{\circ}$, configuration producing a $71.76 \%$ st age efficiency at a pressure ratio of 2.20 . This produced a MGT design point system efficiency of $14.85 \%$ at $993 \mathrm{~W}$, matching prime movers in the latest commercial DCHP units.

Cost and $\mathrm{CO}_{2}$ savings were $10.7 \%$ and $6.3 \%$ respectively for annual power demands of 17.4 MWht and 6.1 MWhe compared to a standard condensing boiler (with grid) installation. The maximum cost saving (on design point) was $14.2 \%$ for annual power demands of 22.62 MWht and 6.1 MWhe corresponding to an $8.1 \% \mathrm{CO}_{2}$ saving. When sizing, maximum savings were found with larger heat demands. When sized, maximum savings could be made by encouraging more electricity export either by reducing household electricity consumption or increasing machine efficiency.

\footnotetext{
* Corresponding author: Mechanical Engineering and Design, School of Engineering and Applied Science, Aston University, Aston Triangle, Birmingham, B4 7ET, UK. email: claya@aston.ac.uk
} 


\section{Introduction}

The feasibility of a Micro Gas Turbine (MGT) Domestic Combined Heat and Power (DCHP) unit was previously assessed [1] wherein current technological limits suggested a net power, $\dot{W}_{n e t}$, of $1 \mathrm{kWe}$ would produce a system efficiency, $\eta_{s}$, of 15\%, an improvement over existing (12\%) [2] and latest (14\%) [3] commercial DCHP prime movers. Higher system efficiencies are required to provide better financial and environmental incentives to the consumer [4]. The use of a turbocharger bearing platform is, at present, an accessible technology and remains a simple method for producing a low-cost unit within a marketable price range. This paper investigates the potential for a MGT DCHP through the design, and performance analysis of a micro compressor by Computational Fluid Dynamics (CFD).

\section{Outline Compressor Design}

To allow the use of oil cooled journal bearings, shaft speeds less than 220,000 $\mathrm{rev} / \mathrm{min}$ were required in a device which will deliver a target pressure ratio, $r_{c}$, of 2.15 at a compressor efficiency, $\eta_{c}$, of $73 \%$. To avoid the use of parasitic devices or compressor bleeding, other micro compressors with similar MGT duties are looking to adopt non-contact aerodynamic air foil bearings [5] which require a high temperature conformal coating [6] for shaft speeds of 500,000 rev/min with an impeller diameter of $20 \mathrm{~mm}$. The stage efficiency disadvantages of small, high speed impellers are two fold: firstly, relative tip clearance increases due limitations in manufacturing tolerancing, and secondly, a Reynolds number reduction suggests a reduced aerodynamic efficiency [7]. In a bulkier set up, the speed limitation of the oil cooled journal bearing will require a $40 \mathrm{~mm}$ impeller diameter and restricts maximum attainable pressure ratio. However, and in spite of a system efficiency penalty [8], a lower pressure ratio can increase compressor stage operating range [9] which is an important criterion for DCHP during periods of low power demand. The performance advantages of slightly larger turbomachinary components would seem to outweigh the size penalty in a DCHP application where MGTs have a natural advantage over existing prime movers such as Stirling or Internal Combustion Engines (ICEs). 


\section{1D Compressor design methodology}

Centrifugal stress was accommodated for by specifying the discharge tangential velocity component, $U_{2},<470 \mathrm{~m} / \mathrm{s}$ to permit the use of AIC355 T6 alloy [9], a material currently used in the mass manufacture of centrifugal impellers by investment casting for turbo chargers. An inlet shroud blade angle, $\beta_{1 s}$, of around $61^{\circ}$ was used to provide maximum flow capacity [10], a characteristic shared by most modern impeller inlets [11]. Mach numbers were limited to < 0.7 [10]. An absolute discharge flow angle, $\alpha_{2 m}$, of $65^{\circ}$ was selected to prevent reverse flow in th e vaneless diffuser [12] [13]. A mass flow, $\dot{m}$, of $20 \mathrm{~g} / \mathrm{s}$ reflected the $1 \mathrm{~kW}$ MGT net power, $\dot{W}_{n e t}$, requirement and target pressure ratio, $r_{c}$. The $1 \mathrm{D}$ compressor stage efficiency, $\eta_{c}$, was set to $75 \%$.

The remaining variables were calculated by continuity of mass, equation of state, Euler's turbomachinary equation and vector diagrams. The remaining variables: blade backsweep, $\beta_{b 2}$, shaft speed, $\omega$, impeller inlet hub radius, $r_{1 h}$, and impeller discharge radius, $r_{2}$, were varied in the optimization process.

It is generally considered that increasing blade backsweep, $\beta_{b 2}$, will provide a more stable and wider operating range [12] due to improved diffusion resulting from a uniform flow pattern at discharge [14]. From a geometric perspective increasing blade backsweep, $\beta_{b 2}$, was shown to increase required blade height, $b_{2}$, and reduce pressure ratio, $r_{c}$, at constant shaft speed, $N$; or increase blade height, $b_{2}$, and shaft speed, $N$, at constant pressure ratio, $r_{c}$; see Figure 1.

Previous investigators [5] [15] have preferred to design micro impellers on the basis of specific speed between $0.6-0.8$ for optimal efficiency [16]. Due to the lower speed restrictions of the journal bearing platform, the specific speed range for this design was $0.4-0.5$, far below the optimum even with the largest blade backsweep. 


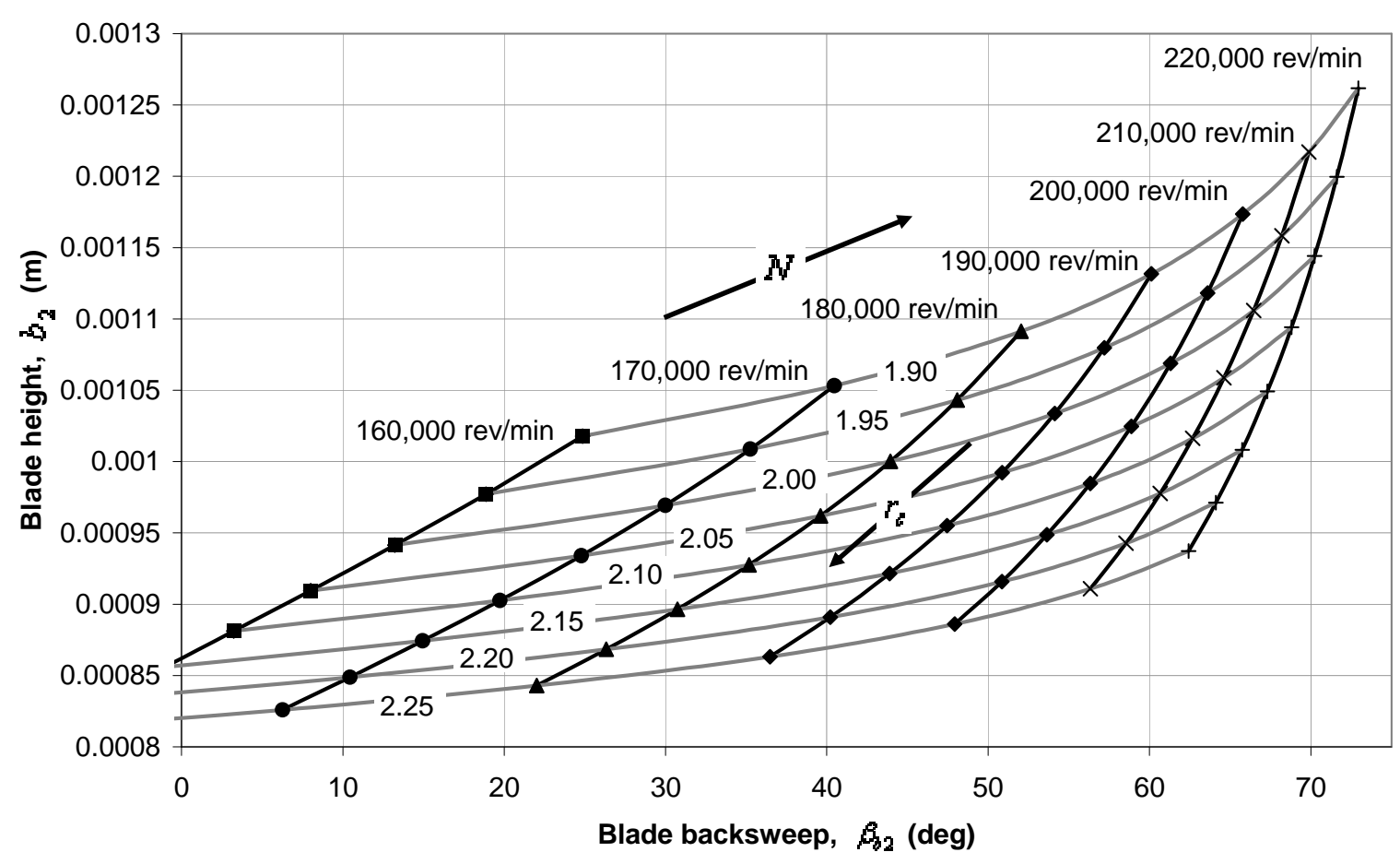

Figure 1 Relationship describing the effect of increased blade height, $b_{2}$, from increasing blade backsweep, $\beta_{b 2}$, and its impact of reducing pressure ratio, $r_{c}$, with limiting shaft speed, $N$.

\section{3D Compressor geometry definition}

A design code was written in Matlab ${ }^{1}$ which produced .txt and .jou files needed to describe the coordinates and geometry construction of the centrifugal impeller for use by Gambit $^{2}$ (geometry modelling software). Bezier splines were used to describe the meridional profile whilst polar coordinates were used to describe the radial location of each parametric interval. The camber and blade angles were subsequently calculated following [13]. The Bezier equations were first represented in an Excel ${ }^{3}$ spreadsheet where 2D plots representing the Meridional profile and Camber line were initially used to examine blade curvature. Flow area was calculated using a trapezoidal function at each parametric interval, across the channel and between the

\footnotetext{
${ }^{1}$ The Mathworks, Inc., 3 Apple Hill Drive, Natick, MA 01760-2098, USA. Version 7.6.0 (R2008a).

${ }^{2}$ ANSYS, Inc., Southpointe, 275 Technology Drive, Canonsburg, PA 15317, USA. Gambit version 2.4.6.

${ }^{3}$ Microsoft Corporation, One Microsoft Way, Redmond, WA 98052-7329, USA. Microsoft@ Office Excel 2003 (11.8307.8221) SP3.
} 
hub and shroud contours. The parametric intervals of the hub contour were iterated to ensure the calculated flow area would be perpendicular to the mean flow path between the hub and shroud contours.

A 3D examination of the blade curvature was performed via Solidworks ${ }^{4}$ using a design table linked to the Excel spreadsheet. In Excel, slight iterations were made to the meridional profile and polar coordinates of the parametric points which instantly updated the Solidworks model. Once satisfied with the consistency of curvature [9] and flow area to promote stable flow, the final coordinates were read from the spreadsheet by the Matlab code to generate the .txt and .jou files for geometry generation in Gambit. The mesh was then exported into Fluent ${ }^{5}$ (CFD software) where it was solved 3 dimensionally. No additional commercial software was required.

\section{CFD methodology}

The flow model consisted of inducer, channel and diffuser fluid volumes along the axial direction each with individual tip clearance volumes. A rotational periodic condition was set up using a single channel with interior faces between the inducer/channel, channel/diffuser volumes and channel/channel tip clearance. The channel volume consisted of the flow volume around the splitter between blade pressure side to blade suction side; see Figure 2.

\footnotetext{
${ }^{4}$ DS Solidworks Headquarters, Dassault Systèmes Solidworks Corp., 300 Baker Avenue, Concord, MA 01742. Version 2008 SP4.0

${ }^{5}$ ANSYS, Inc., Southpointe, 275 Technology Drive, Canonsburg, PA 15317, USA. Fluent version 6.3.26.
} 


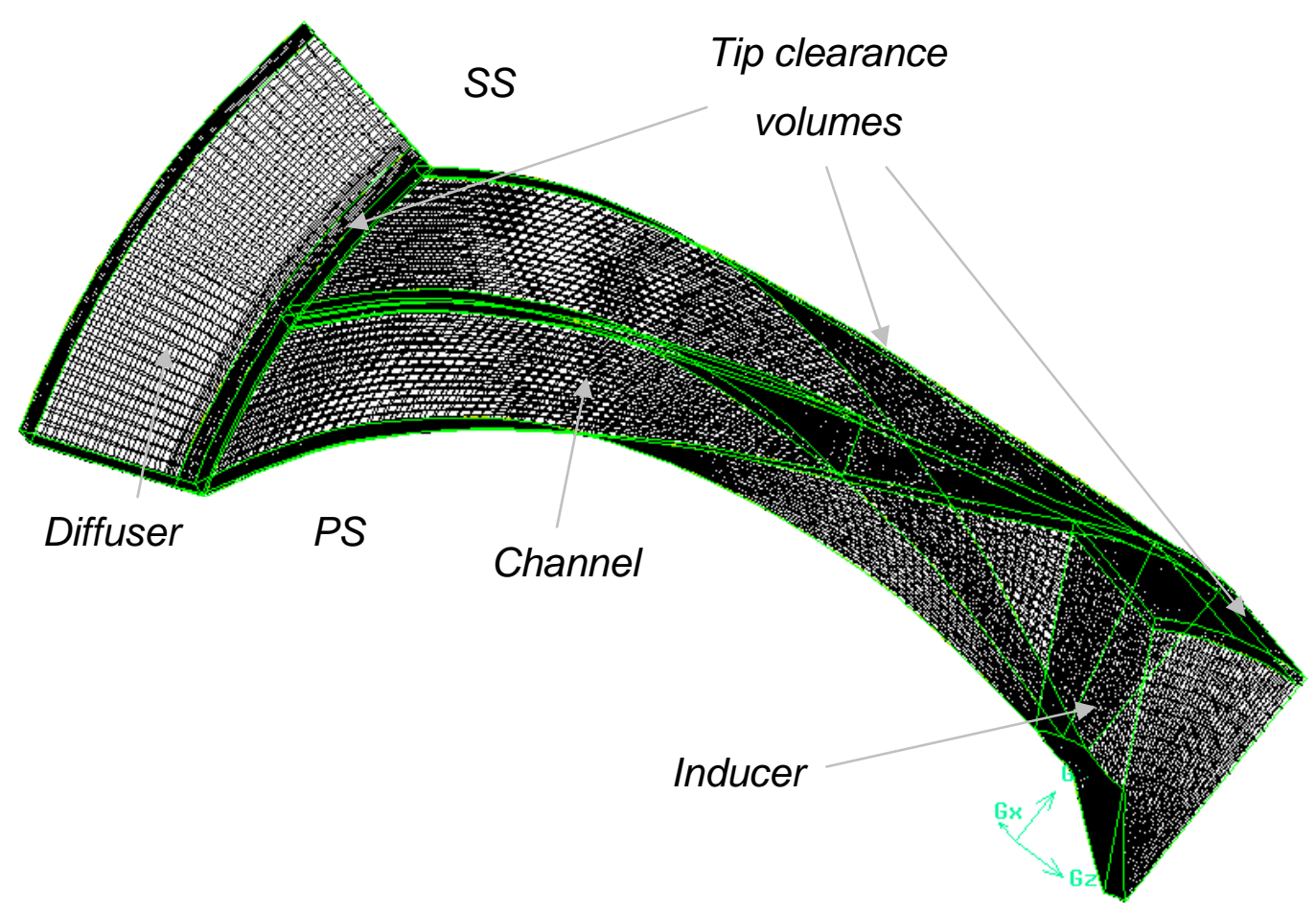

Figure 2 Impeller was modelled as a single rotating channel volume with splitter, separated from stationary volumes; inducer, diffuser and tip clearance by interior faces. Periodic functions were arranged at the pressure and suction sides (PS \& SS) of inducer and diffuser.

An implicit, steady, pressure-based solver was used. The RNG k- $\varepsilon$ viscous turbulence model was used due to the curved surfaces with non-equilibrium wall functions and viscous heating to account for compressibility affects [17]. Based on Hydraulic diameter, other investigations saw Reynolds numbers less than 5000 for the smallest 3D micro compressors [18] close to the laminar/transition region used in pipe flow analogy. In this investigation calculated Reynolds number were 15,000 at design point following [19] suggestion that the use of turbulence modelling was suitable.

The material was air, modelled as an ideal gas with a piecewise polynomial function for specific heat capacity. Under-relaxation factors were conservative between 0.1 or 0.2 . Residual convergence monitors were set to $1 x^{-05}$. Convergence also used a force monitor with a moment coefficient on the blade surfaces and required mass flux imbalance to be less than $1 x^{-08} \mathrm{~kg} / \mathrm{s}$ for a mass flow of $2 x^{-02} \mathrm{~kg} / \mathrm{s}$. The SIMPLE pressure-velocity coupling solution was invoked. Grid convergence was achieved at around 500,000 elements, but reasonable and conservative values for stage efficiency and pressure ratio were achieved at 100,000 elements; at which grid 
densities stage efficiency, $\eta_{c}$, was under predicted by $2 \%$ and pressure ratio, $r_{c}$, was under predicted by $3.5 \%$. All discretization was first order upwind apart from pressure which was standard. In the interests of time, solutions with low mesh densities and first order discretization were used to produce conservative solutions suitable for comparison between different impeller geometries.

A tip clearance of $0.3 \mathrm{~mm}$ was measured and used from a Garrett turbocharger $^{6}$ to reflect the manufacturing accuracy of mass produced turbomachinary components and radial growth at similar operating speeds. Splitters were positioned approximately $2 / 3$ up the channel. Splitter blades are used to give wider range during off-design [20] but in addition splitters brought a $1 \%$ efficiency increase across the stage at design point likely due to limiting slip effects. Splitter position sensitivity has been found to provide a stage efficiency increase of between 1-2\% at design point [21]. No investigation into splitter position was performed in this study. All reported efficiencies are based on total properties unless otherwise stated.

\section{3D Design point optimization}

\subsection{Blade Backsweep}

An initial two-zone impeller optimization code following [12] was developed but later aborted when the impact of input variables could not be assessed from the results. Instead, outline impeller geometry and static pressure values were established from simple 1D meanline analysis. Several impeller geometries (denoted a to $f$ ) were created by adjusting blade backsweep, $\beta_{b 2}$, at different shaft speeds, $N$, to deliver a pressure ratio, $r_{c}$, of 2.15 . Inlet hub blade angle, $\beta_{1 h}$, mass flow, $\dot{m}$, and inlet hub radius, $r_{1 h}$, remained constant; see Figure 3. Only impellers $a(159)$ and $b(319)$ are shown to have decelerating flow, $D R_{2}>1$ whilst the others had accelerating, $D R_{2}<1$ flow (see Table 1 for details of each impeller).

\footnotetext{
${ }^{6}$ Honeywell International Inc., 101 Columbia Road, Morristown, NJ 07962, USA. Garrett Turbochargers by Honeywell, Small frame, GT12(41) family.
} 
These impeller geometries were assessed in 3D using CFD, each with a diffuser length of $5 \mathrm{~mm}$; see Figure 4 . Varying backsweep angle, $\beta_{b 2}$, between $15^{\circ}$ and $54^{\circ}$ resulted in a gentle downward trend in impe ller efficiency, $\eta_{i}$, and a fluctuating downward trend in total stage pressure ratio, $r_{c}$, stage efficiency, $\eta_{c}$, showed little change, and impeller pressure ratio decreased, again with a fluctuation at impeller $c(449$.

In larger machines, stage efficiency, $\eta_{c}$, should increase by $1-2$ points for every $10^{\circ}$ of blade backsweep, $\beta_{b 2}$ [12]. Plus at micro scale, a reduction in blade height, $b_{2}$, has shown to cause an efficiency penalty by reducing relative tip clearance thus increasing aerodynamic loss [22]; neither of which present themselves here.

The trend for increasing total stage pressure ratio, $r_{c}$, for decreasing blade backsweep, $\beta_{b 2}$, is confirmed by the 1D calculations of Figure 1 in terms of total pressure ratio. According to [14] increased blade backsweep, $\beta_{b 2}$, accelerates the flow, which reduces diffusion and blade loading within the impeller, minimizing secondary flow development to improve impeller efficiency but reduce static pressure generation. Reducing diffusion is clearly seen in 1D from Figure 3 but not reflected in the 3D results. In this investigation, accelerated flow is attributed to decreasing discharge area or blade height, $b_{2}$, a consequence of reduced blade backsweep, $\beta_{b 2}$. Increased kinetic energy explains increasing total pressure ratio within the impeller and stage with decreasing blade backsweep, $\beta_{b 2}$, and increased impeller efficiency, $\eta_{i}$. Without aerodynamic losses from reduced blade height, $b_{2}$, the characteristics here are more like conventional sized impellers than the smaller diameter micro impellers seen in other investigations.

Improved impeller efficiency, $\eta_{i}$, from reduced blade backsweep, $\beta_{b 2}$, is a consistent observation with [20] and numerical data using total properties from [14]. Slight improvements in impeller efficiency, $\eta_{i}$, can also be attributed to reduced friction from a smaller meridional chord or flow path length. In this investigation, blade wrap angle was reduced from $95^{\circ}$ on impeller $e$, to $55^{\circ}$ on impeller $a$.

Cross referencing Figure 3, Figure 4, and previous work suggests compressor performance is a trade off among diffusion ratio, $D R_{2}$, blade height, $b_{2}$, blade 
backsweep, $\beta_{b 2}$, and inlet conditions (reducing shaft speed, $N$, reduced the meridional component, $C_{m 1}$, and area, $A_{1}$, at inlet by lowering the impeller tangential component, $\left.U_{1 h}\right)$. Further investigation was performed and is presented below.

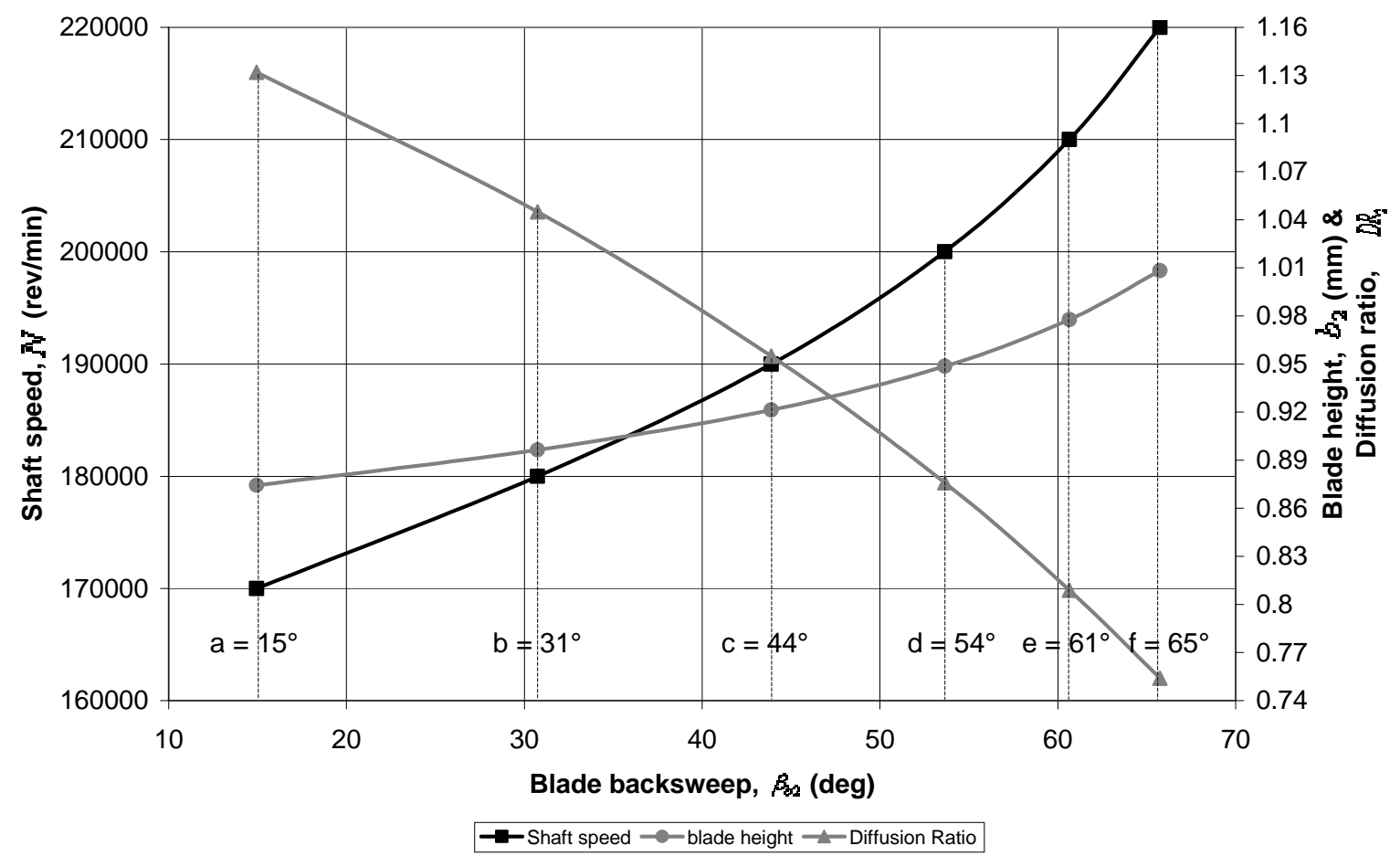

Figure 3 Diffusion ratio, $D R_{2}$, and blade height, $b_{2}$, established from 1D meanline analysis of compressor impellers with varying blade backsweep, $\beta_{b 2}$, forced to run at different shaft speeds, $N$, by assigning constant pressure ratio, $r_{c}$, of 2.15 and rotor diameter, $r_{2}$ of 40 mm. 


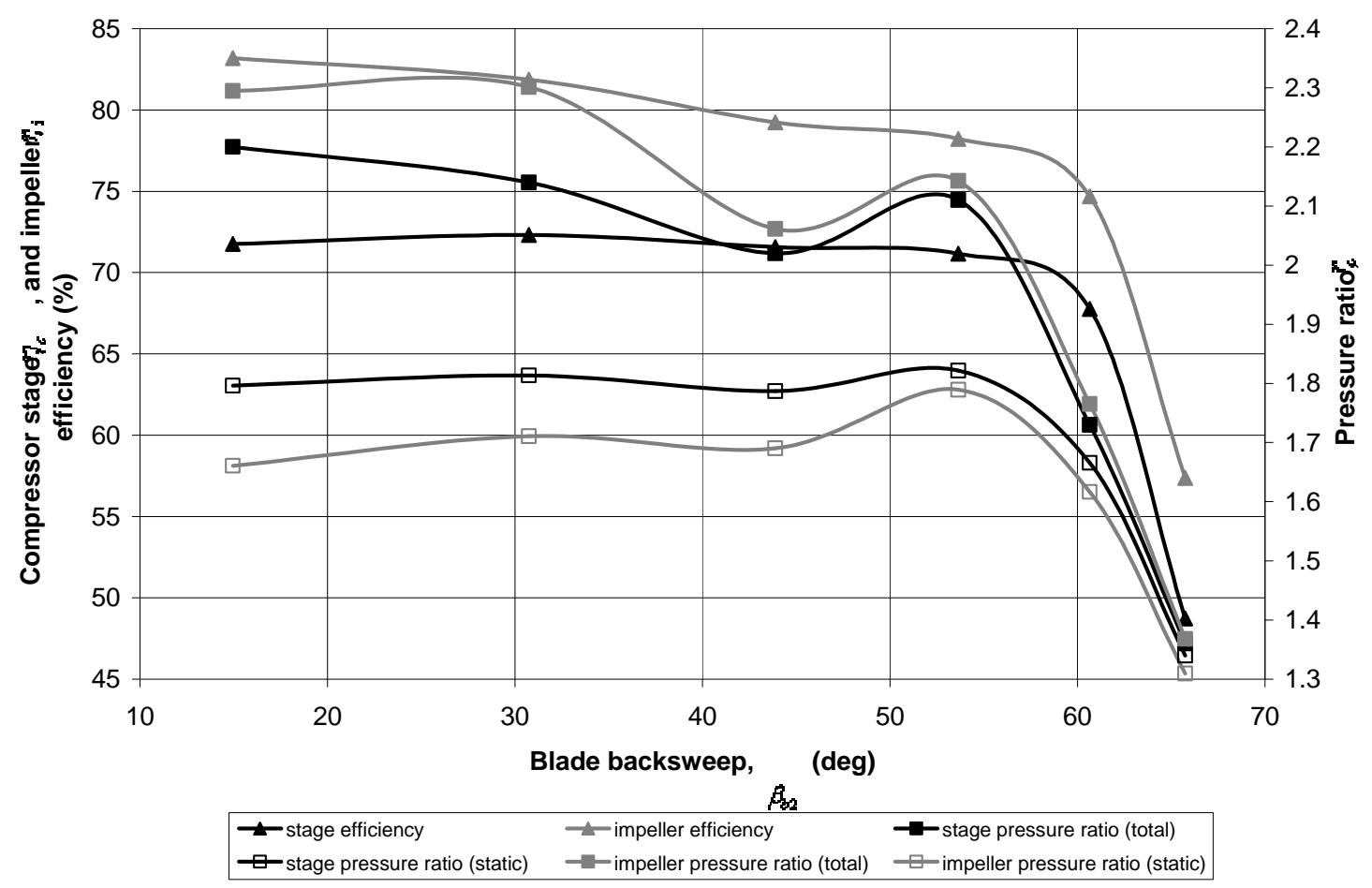

Figure 4 Compressor stage efficiency, $\eta_{c}$, impeller stage efficiency, $\eta_{i}$, and pressure ratio, $r_{c}$, established from CFD calculations using the impellers generated for Figure 3.

\subsection{Blade height}

Figure 4, demonstrated that the slowest impellers with minimum blade backsweep, $\beta_{b 2}$, produced the greatest diffusion ratios, $D R_{2}$, with the smallest blade heights, $b_{2}$. At $1 \mathrm{D}$, reducing blade backsweep, $\beta_{b 2}$, raised diffusion ratio, $D R_{2}$, by increasing the discharge relative velocity component, $W_{2}$, from an increase in the discharge tangential velocity component, $C_{\theta 2}$. As a consequence the discharge radial component, $C_{m 2}$, must also increase which reduces discharge area, $A_{2}$, and so blade height, $b_{2}$, for a constant tip radius, $r_{2}$.

To independently verify the interplay between backsweep, $\beta_{b 2}$, and blade height, $b_{2}$, on compressor performance, blade height, $b_{2}$, was reduced on impellers $b$ to e compared with impeller a (the smallest) producing impellers $b_{b 2, \min }$ to $e_{b 2, \min }$; relative results with a $5 \mathrm{~mm}$ diffuser length are shown in Figure 5 . For impeller $e$ the reduction in blade height, $b_{2}$, had a very positive impact all round. For the 3 remaining impellers, $b_{b 2, \min }$ to $d_{b 2, \min }$, a reduction in Euler head had an overall negative impact on impeller performance. A consistent impeller efficiency increase 
with diffusion ratio, $D R_{2}$, reduction is found for impellers $b_{b 2, \min }$ to $e_{b 2, \min }$. With less diffusion, the efficiency improvement clearly occurs as a result of accelerating flow from a reduction in discharge area, $A_{2}$, to produce stable flow with less instability as outlined previously.

The percentage difference in pressure ratio, $r_{c}$, between predicted 1D mean flow and 3D CFD was very small, as shown in Table 2. This suggests the production of a minimal secondary or wake flow region since 1D meanline analysis only accounts for the primary or jet flow.

The following constants were used for the cycle analysis: turbine efficiency, $\eta_{t}, 75 \%$, mechanical efficiency, $\eta_{m}, 90 \%$, burner efficiency; $\eta_{b}, 98 \%$, recuperator effectiveness, $\eta_{H E X}, 75 \%$, pressure drop value, $P, 90 \%$.

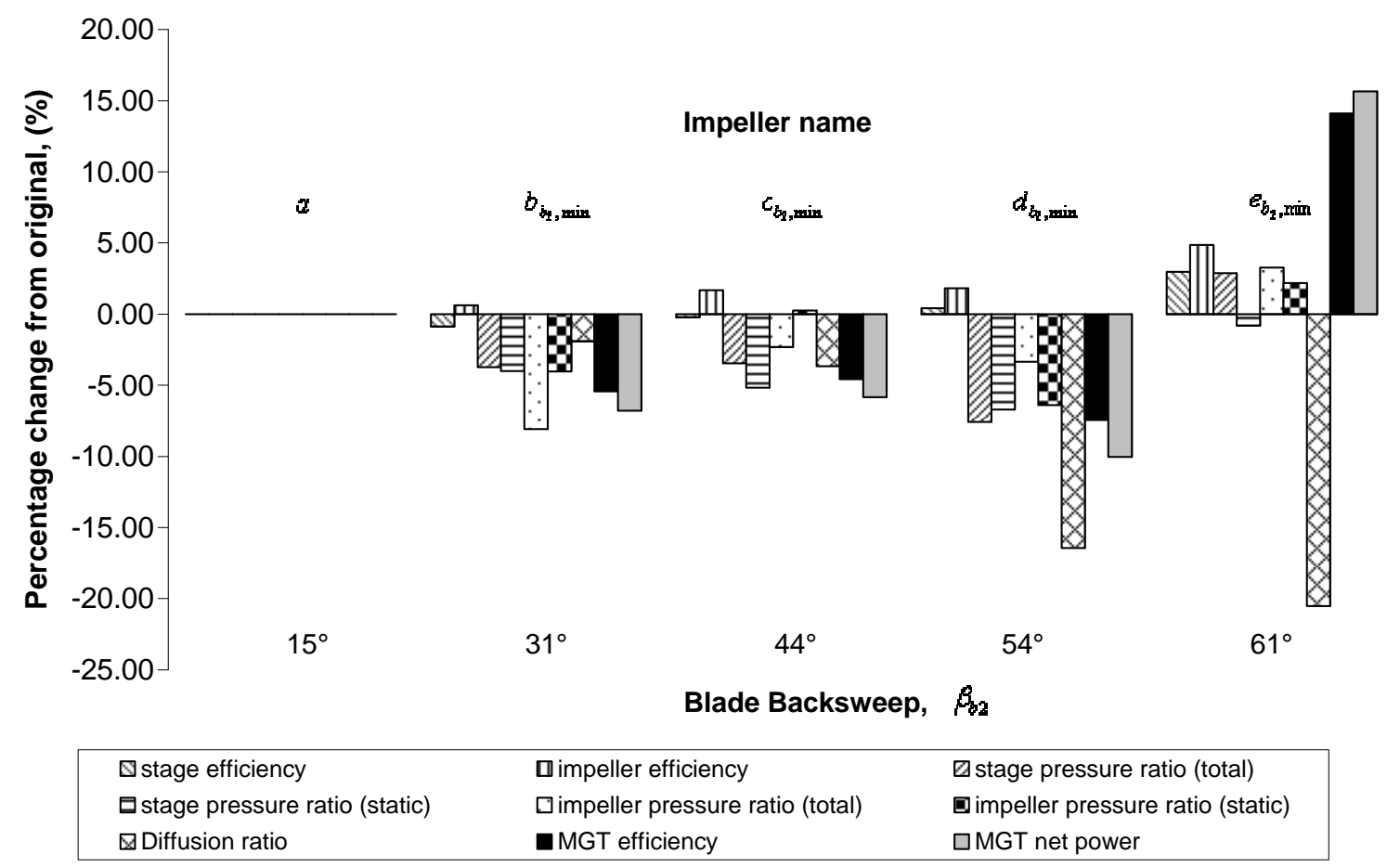

Figure 5 Percentage change of compressor and MGT performance with compressor impellers of different blade backsweep, $\beta_{b 2}$, and shaft speed, $N$, after using inlet conditions and small blade height, $b_{2}$, from impeller a. Compare with Figure 4.

Table 1 Impeller summary

Impeller Backsweep [ 9 Speed [rev/min] Blade height [mm] $D R_{2}$
a
15
170,000
0.874
1.13 


$\begin{array}{ccccc}\text { b } & 31 & 180,000 & 0.896 & 1.04 \\ \text { c } & 44 & 190,000 & 0.921 & 0.96 \\ \text { d } & 54 & 200,000 & 0.949 & 0.88 \\ \text { e } & 61 & 210,000 & 0.978 & 0.81 \\ f & 65 & 220,000 & 1.00 & 0.75\end{array}$

Table 2 Difference between predicted 1D meanline and 3D CFD results of pressure ratio, $r_{c}$, before and after changing blade height.

$\begin{array}{cccc}\text { Impeller } & \text { 1D predicted } & \text { 3D CFD result } & \text { percentage difference(\%) } \\ a & 2.15 & 2.20 & 2.27 \\ b & 2.15 & 2.14 & -0.47 \\ c & 2.15 & 2.02 & -6.44 \\ d & 2.15 & 2.11 & -1.90 \\ e & 2.15 & 1.73 & -24.23 \\ & & & \\ b_{b 2, \min } & 2.08 & 2.06 & -0.96 \\ c_{b 2, \min } & 2.02 & 1.95 & -3.47 \\ d_{b 2, \min } & 1.92 & 1.95 & 1.56 \\ e_{b 2, \min } & 1.76 & 1.78 & 1.14\end{array}$

\subsection{Inlet geometry}

Impellers are traditionally designed with enough relative diffusion to provide a controlled maximum static pressure rise for stable combustion downstream (typically fluid velocity $<90 \mathrm{~m} / \mathrm{s}$ [23]). Diffusion ratio, $D R_{2}$, can be increased by increasing the inlet meridional velocity component, $C_{m 1}$, to reduce inlet area, $A_{1}$, and raise inlet relative shroud velocity, $W_{1 s}$. In this exercise the inlet meridional velocity component, $C_{m 1}$, was increased by increasing the inlet hub radius, $r_{1 h}$, whilst maintaining the optimum inlet blade shroud angle, $\beta_{1 s}$, of $61^{\circ}$ with a $5 \mathrm{~mm}$ diffuser length. Impeller $d$ was the baseline; relative results are shown in Figure 6. Reducing inlet area $A_{1}$, to raise the diffusion ratio, $D R_{2}$, by increasing inlet relative shroud velocity, $W_{1 s}$, 
worsened compressor performance most likely due to increased blockage effects [20].

For a low stage pressure rise impeller, the magnitude of dynamic pressure conversion or diffusion demand is less. Providing the dynamic portion of the total pressure is small enough to maintain combustion downstream, relative diffusion can be limited to provide maximum impeller efficiency.

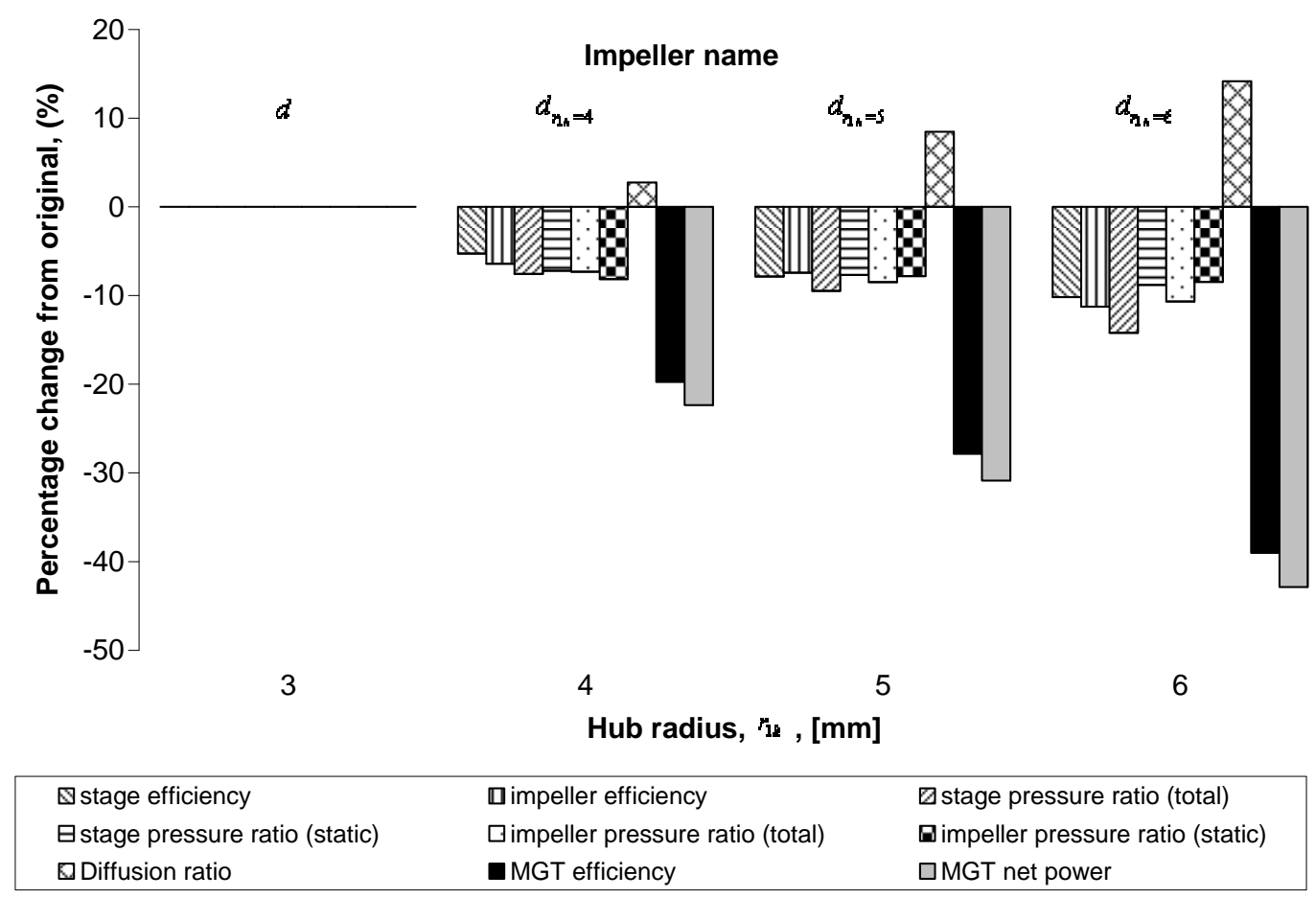

Figure 6 Percentage change of compressor and MGT performance of impeller $d$ when inlet hub radius, $r_{1 h}$, is increased to increase diffusion ratio, $D R_{2}$, by reducing inlet area, $A_{1}$, against a constant discharge area, $A_{2}$.

\section{Compressor off design}

A 3D CFD off-design study was performed on impellers $a$ and $d$ see Figure 7 . These impellers showed similar on-design performance but with opposing characteristics; low-speed, small blade backsweep vs. high-speed, large blade backsweep. A large blade backsweep can improve off-design performance, whilst lower speeds are beneficial for various mechanical reasons.

Without test data, suitable static pressure values for the mass flow inlet, pressure outlet boundaries and operating pressure were found by conducting 1D 
compressor off-design analysis. Iterations on inlet static temperature, $T_{1}$, and discharge radial velocity component, $C_{m 2}$, to preserve mass continuity established 1D solutions from outline geometry. 1D efficiency was calculated following [24] based on iterating the pipe flow friction factor using the Colebrook-White equation.

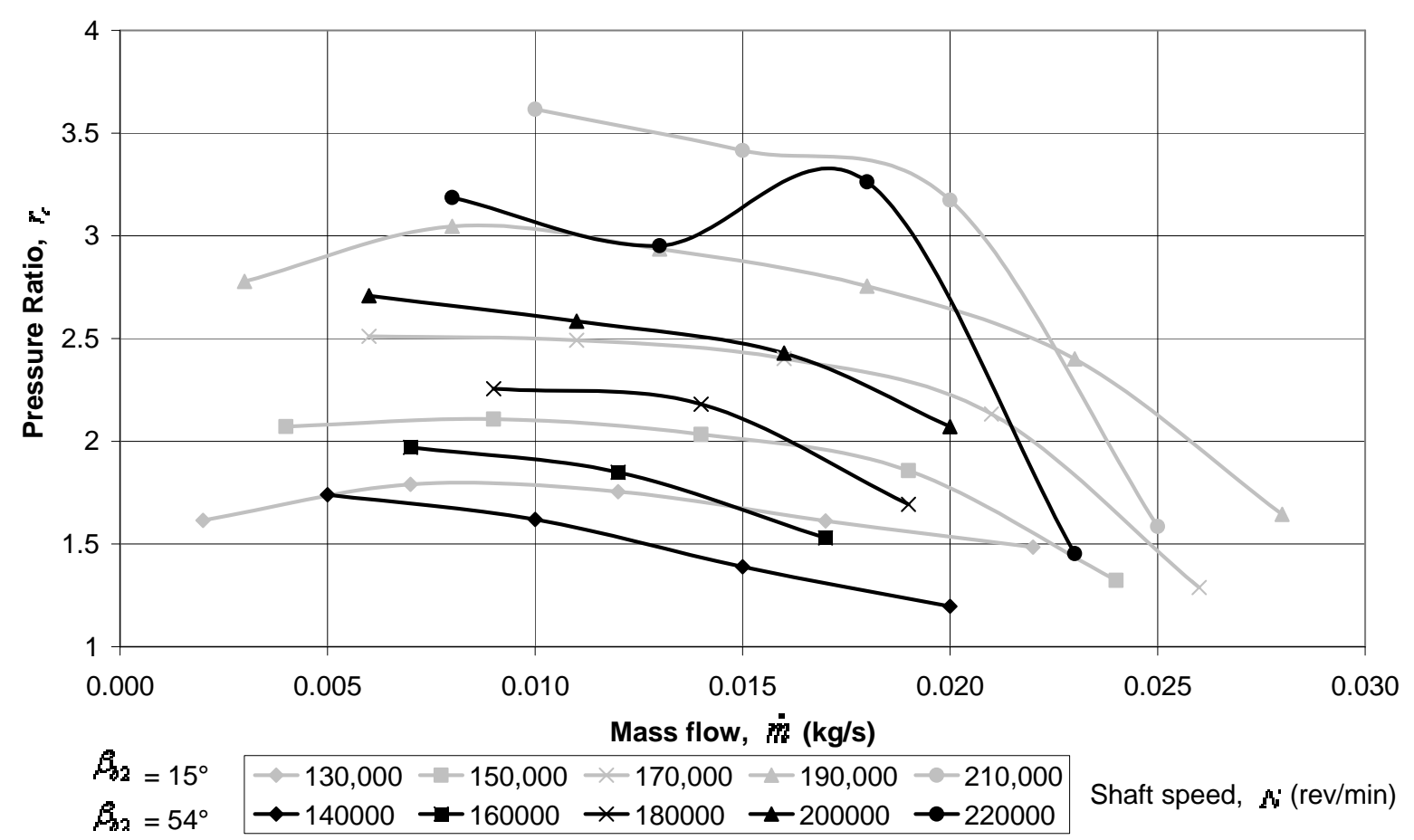

Figure 7 3D off-design compressor map from CFD for impeller $a$ and impeller $d$

\section{Off design MGT performance curve}

In order to use the compressor map to establish gas turbine performance, an algorithm was written to establish the Turbine Inlet Temperature (TIT) and system efficiency, $\eta_{s}$, from the pressure ratio, $r_{c}$, stage efficiency, $\eta_{c}$, and mass flow, $\dot{m}$, at each compressor off-design point. The compressor off-design pressure ratio, $r_{c}$, was matched with an optimum pressure ratio, $r_{c}{ }^{\prime}$, calculated by Brayton cycle analysis, see Figure 8 for more details. The resulting gas turbine performance from each compressor off-design point produced the scatter shown in Figure 9 and Figure 10 for impellers $a$ and $d$ respectively. From the scatter, a curve based on distinct gas turbine operating points operating on a least fuel operating strategy was fitted. Absence of scatter indicates a least fuel off-design operating strategy is not possible in that region, hence the curves represent best possible off-design performance in 
terms of least fuel. By definition the off-design strategy assumes variable speed for maximum system efficiency [25] which will require inverter electronics.

The cycle analysis constants from Part 6 were again used here: mechanical efficiency, $\eta_{m}, 90 \%$, burner efficiency; $\eta_{b}, 98 \%$, recuperator effectiveness, $\eta_{H E X}$, $75 \%$, pressure drop value, $P, 90 \%$. To account for off design turbine efficiency, $\eta_{t}$, remained $+2 \%$ higher than the compressor efficiency [22]. A $3^{\text {rd }}$ order polynomial function was fitted to each performance curve to describe the off-design relationship between net power, $\dot{W}_{n e t}$, and system efficiency, $\eta_{s}$. The equations are shown below;

$$
\begin{aligned}
& \beta_{b 2}=15^{\circ}, \eta_{s}=2.9600 \times 10^{-8} W_{n e t}^{3}-6.2896 \times 10^{-5} W_{n e t}^{2}+4.7158 \times 10^{-2} W_{n e t}+8.0716 \times 10^{-1} 1 \\
& \beta_{b 2}=54^{\circ}, \eta_{s}=4.5510 \times 10^{-8} W_{n e t}^{3}-7.5987 \times 10^{-5} W_{n e t}^{2}+4.6941 \times 10^{-2} W_{n e t}+6.2097 \times 10^{-1} \mathbf{2}
\end{aligned}
$$

\begin{tabular}{|c|c|c|c|c|c|c|c|}
\hline \multirow{6}{*}{$\begin{array}{c}3 \\
\text { Selecting the TIT } \\
\text { which enables the } \\
\text { compressor point } \\
\text { to run at its } \\
\text { optimum }\end{array}$} & $\eta_{\mathrm{s}}$ & $W_{\text {net }}$ & $\mathrm{T}_{03}$ & $r_{c}^{\prime}$ & $\eta_{s}$ & $W_{\text {net }}$ & \multirow{6}{*}{$\begin{array}{c}4 \\
\text { Each compressor point } \\
\text { is analyzed and } \\
\text { plotted, see Figure } 9 . \\
\text { Curve is fitted to } \\
\text { example point } 2 \text { not } \\
\text { point } 1 \text { due to a lower } \\
\text { fuel rate and higher } \\
\text { efficiency }\end{array}$} \\
\hline & 1.48 & 84.6 & 975 & 2.1 & 1.86 & 102.1 & \\
\hline & 4.01 & 247.3 & 1025 & 2.2 & 4.10 & 246.1 & \\
\hline & 6.22 & 410.1 & 1075 & 2.4 & 6.22 & 410.0 & \\
\hline & 8.15 & 572.8 & 1125 & 2.6 & 8.20 & 590.0 & \\
\hline & 9.85 & 735.6 & 1175 & 2.7 & 10.08 & 778.0 & \\
\hline
\end{tabular}

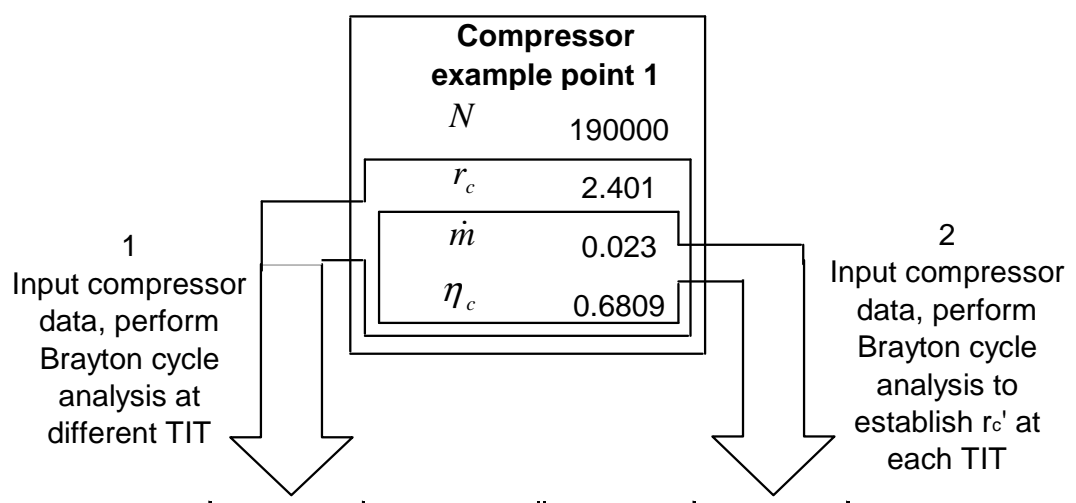

Figure 8 Algorithm flow chart Off-design. This algorithm was used to calculate each of the points in the scatter plot of Figure 9 and Figure 10. 


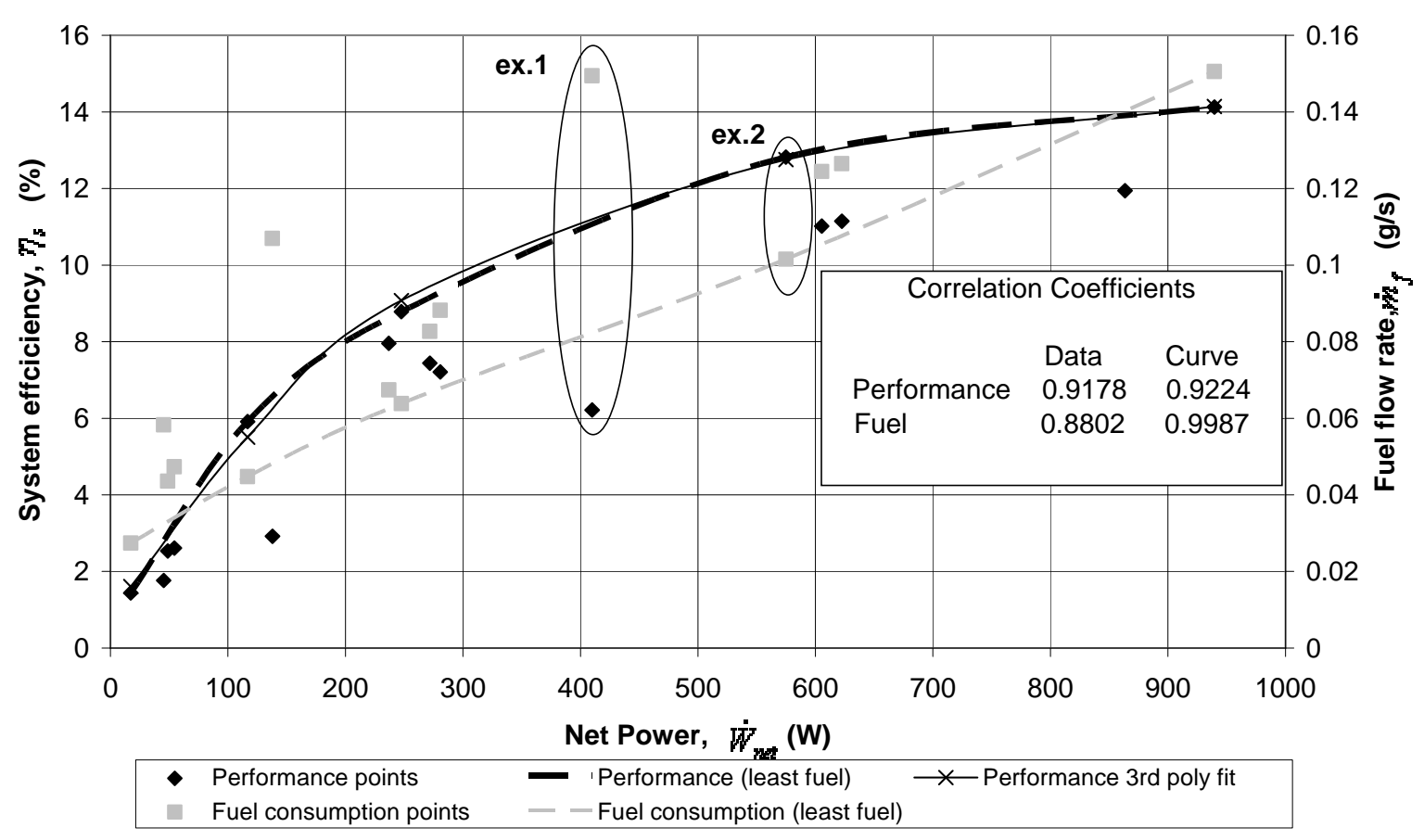

Figure 9 Calculated MGT off design performance for impeller $a, 15^{\circ}$ blade backsweep, $\beta_{b 2}$, impeller. Illustrated is the comparison between example point 1 shown explicitly in Figure 8 and example point 2 which, like every other scatter point, was calculated in a similar way. The fitted curve passed through example point 2 due to its lower fuel flow rate, $\dot{m}_{f}$.

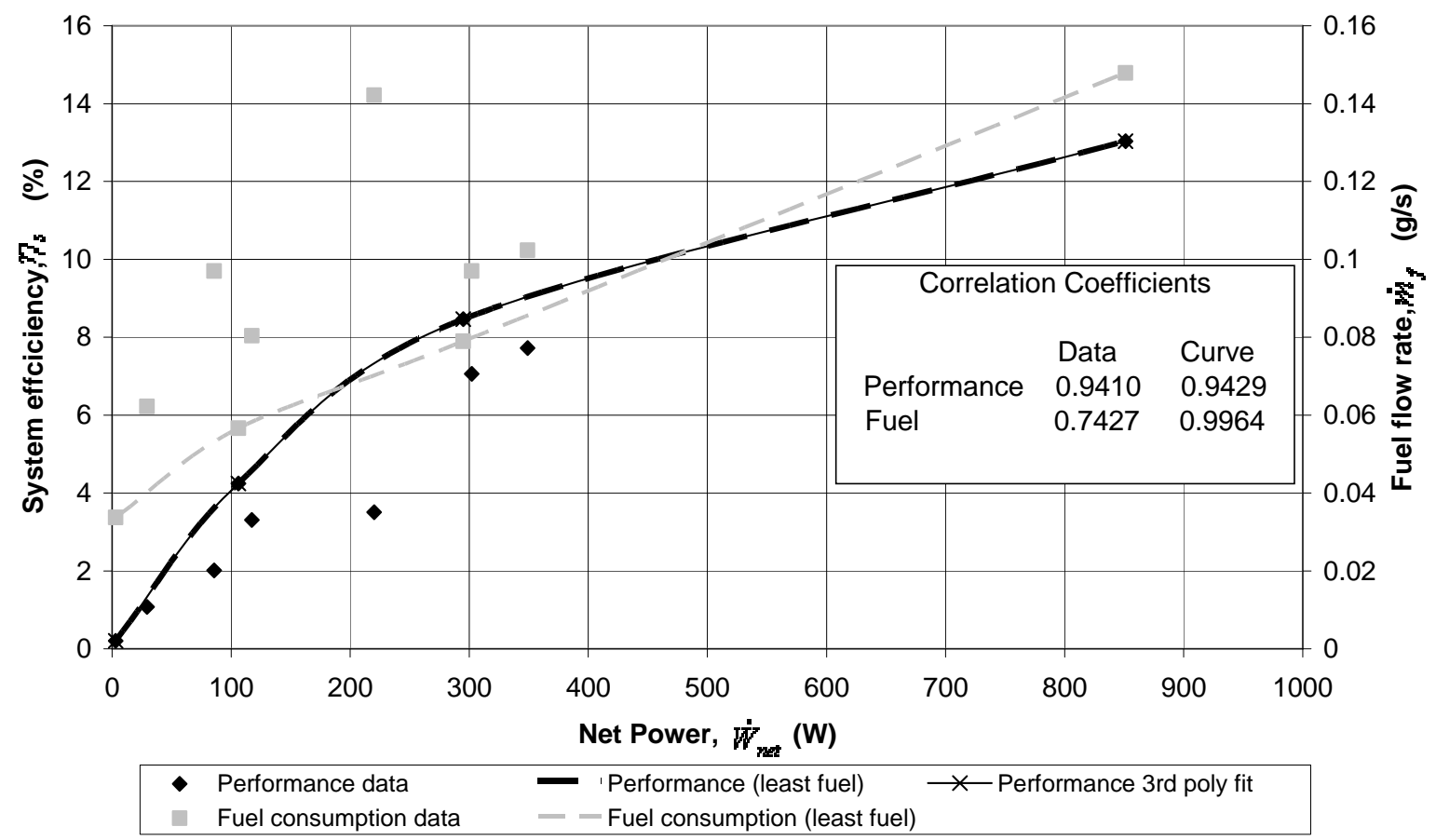

Figure 10 Calculated MGT off design performance for impeller $d, 54^{\circ}$ blade backsweep, $\beta_{b 2}$, impeller. 


\section{Off design MGT DCHP performance}

Annual DCHP performance was predicted using the MGT off design performance curves to account for changes in required power and MGT efficiency from varying seasonal loads. Average monthly power demands for a detached house, the target market for DCHP units, were taken from [26]. For this building the annual loads were 17.4 MWht and 6.1 MWhe. Two other annual thermal loads were analysed at $70 \%$ and $130 \%$ (22.62 MWht and 12.30 MWht) of the average (17.4 MWht) at a range of electrical loads between $20 \%$ to $200 \%$ (2.2 MWhe to 12.2 MWhe) of the average (6.1 MWhe). Using equations 1 and 2 to represent a gas turbine with impellers $a$ and $d$ respectively, monthly DCHP analysis was performed. The analysis assumed a continuous operation strategy, the preferred operating regime for gas turbines and DCHP, utilising thermal storage. The comparative was a standard grid connection with a modern condensing boiler; see Figure 11

In the three scenarios, maximum monthly average DCHP power demands for each annual heat demand were $435 \mathrm{We}, 699 \mathrm{We}, 1039 \mathrm{We}$ (limited to 950We) and $345 \mathrm{We}, 581 \mathrm{We}, 817 \mathrm{We}$ respectively for impellers $a$ and $d$. Due to a superior offdesign performance, impeller a produced larger DCHP savings by generating more electricity for export at specified heat demands.

Generator efficiency, $\eta_{G E N}$, was $85 \%$, exhaust gas to water heat exchanger effectiveness, $\eta_{H E X}$, was $90 \%$, condensing boiler efficiency, $\eta_{C B}$, was $90 \%$, the various cost and emission factors $C_{g}=0.0343, C_{e}=0.1139, C_{e x}=0.05$ [27], $E_{g}=$ $0.194, E_{e}=0.396, E_{e x}=0.396$. The emission factors used in this study were derived from Directive 2004/08/EC which considers exported electricity as 'carbon free' and would displace centrally generated output.

When sizing, for a heat-led machine of specified output power, maximum cost savings are shown to vary with an optimal annual electrical load. The optimal electrical load and maximum cost savings increase with an increasing annual heating load. This is due to the MGT being able to run at a higher output and producing better efficiencies. Less annual heating demand, produced less cost savings but also reduced the optimum height, see the optimum locus for impellers $a$ and $d$ in Figure 11. Reducing sensitivity with respect to the optimum electrical load could provide a more flexible application in terms of cost for lower heating loads. The difference in 
cost savings between the off-design performances of the two gas turbines is less pronounced with larger annual heat demands. Maximum $\mathrm{CO}_{2}$ savings are consistent with the most efficient machine and higher annual heat demands.

When sized, cost and $\mathrm{CO}_{2}$ savings are proportional to electricity export. The magnitude of electricity export is a function of reduced electrical loads, and better prime mover efficiency, as also found during DCHP field trials [4]. For a building with average annual heating demand (17.4 MWht), the average electrical annual electrical load (6.1 MWhe) must decrease by approximately $1 / 3$ for optimum cost savings. This provides users, installers and appliance makers with an incentive to continually reduce electricity consumption with DCHP, which importantly also yields maximum $\mathrm{CO}_{2}$ savings.

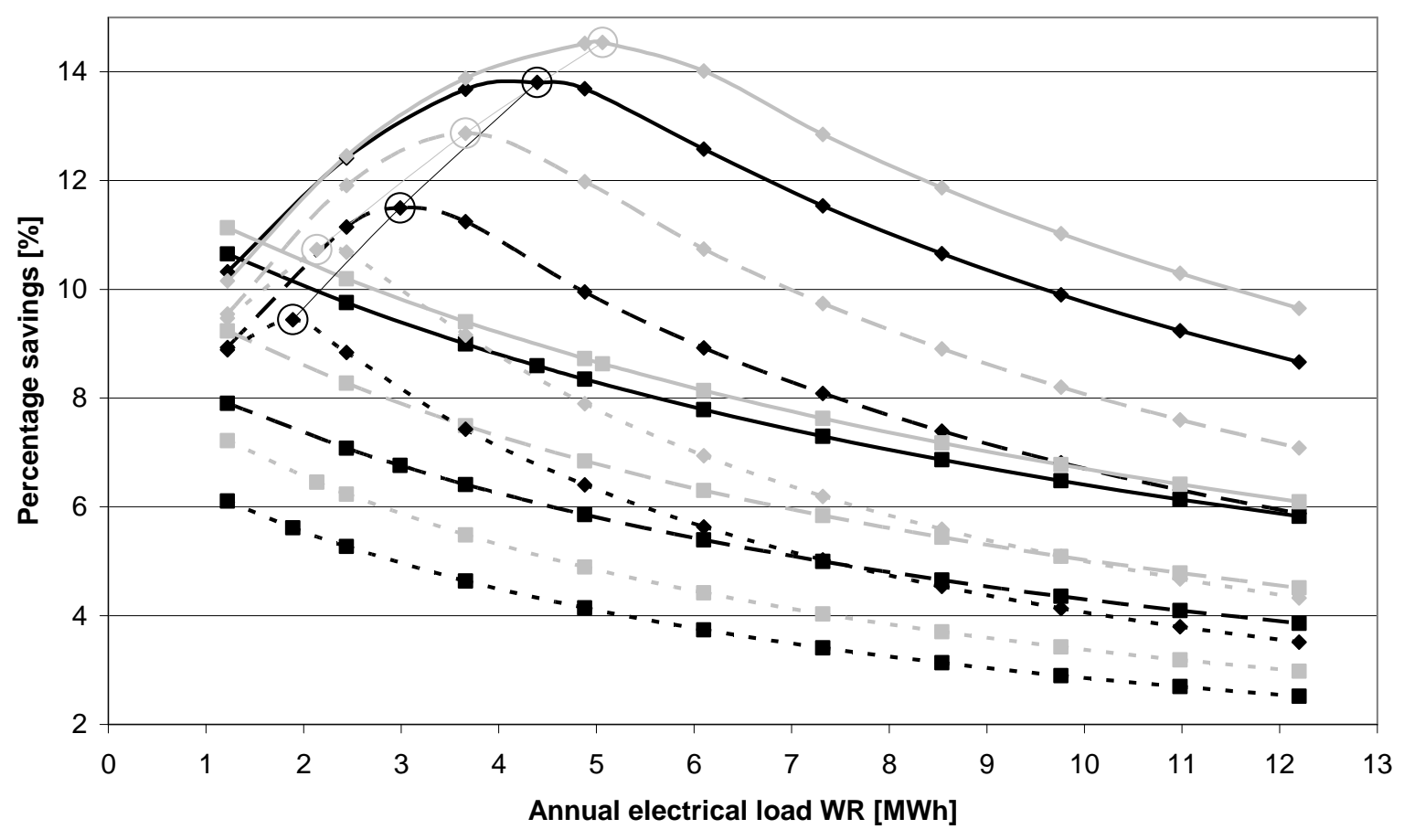

Figure 11 Annual percentage cost (diamond points) and $\mathrm{CO}_{2}$ (square points) savings from DCHP compared to a standard grid connection with condensing boiler at various annual electrical loads for three annual heat loads of 12.8 MWht (dotted line), 17.4 MWht (dashed line), 22.6 MWht (solid line) using a MGT with impeller a (grey line) or $d$ (black line).

\section{Conclusion}

CFD was used to investigate compressors with varying blade backsweep, $\beta_{b 2}$, shaft speed, $N$, and blade height, $b_{2}$. Compressors had low diffusion ratios, $D R_{2}$, due to the rotational speed restrictions on the target pressure ratio from selecting an oil 
cooled journal bearing platform. Increasing the rotational speed would be characterised by a higher specific speed with smaller impeller diameters introducing additional aerodynamic losses and mechanical challenges. Two impellers were chosen for off design performance investigation, small blade backsweep low speed; $\beta_{b 2}=15^{\circ}, \quad N=170,000 \mathrm{rev} / \mathrm{min}, \eta_{c}=71.76 \%, r_{c}=2.20 \mathrm{vs}$. large backsweep higher speed; $\beta_{b 2}=54^{\circ}, \quad N=200,000 \mathrm{rev} / \mathrm{min}, \eta_{c}=71.17 \%, r_{c}=2.11$. The low speed, small backsweep impeller demonstrated superior performance at off-design. The advantages of reducing secondary flow losses by creating more uniform flow from increased blade backsweep were not evident as little or no diffusion took place within the impeller. Instead impeller performance improved by reducing discharge area to accelerate the flow through the impeller. Restricting diffusion is permitted on gas turbine compressors when combustion inlet velocity is low enough to prevent flame blow out. This may be achieved on low pressure ratio impellers since the diffusion duty on an impeller is proportional to the total stage pressure rise.

Design point MGT performances of $\eta_{s}=14.85 \%, \dot{W}_{\text {net }}=993 \mathrm{~W}$ and $\eta_{s}=$ $14.26 \%, \dot{W}_{n e t}=906 \mathrm{~W}$ were established for the small and large blade backsweep impeller compressors respectively. With better off-design performance the small backsweep impeller demonstrated maximal savings. Maximal cost and $\mathrm{CO}_{2}$ savings were found with larger heat demands. For a specified heat demand, maximal cost savings are found with an optimum electrical load which does not coincide with maximal $\mathrm{CO}_{2}$ savings (which increase with reduced electrical load). However, the optimal annual electrical demand for a building with an average thermal load of 17.4 MWht was around $4.0 \mathrm{MWhe}\left(12.9 \%\right.$ cost and $7.5 \% \mathrm{CO}_{2}$ saving), approximately $1 / 3$ less than the corresponding average of $6.1 \mathrm{MWhe}\left(10.7 \%\right.$ cost and $6.3 \% \mathrm{CO}_{2}$ saving) suggesting efforts to reduce cost by reducing electricity consumption will also reduce $\mathrm{CO}_{2}$. Generally speaking, when sized, maximum savings would be made by encouraging more electricity export either by reducing electricity consumption or increasing machine efficiency which would likely occur from an increased electrical output from greater heat demand. 


\section{APPENDIX 1}

\section{Notation}

$\beta_{b 2}$

Impeller tip blade angle

[9]

$b_{2} \quad$ Impeller tip blade height

[mm]

$C_{g}$

Gas tariff

[£0.01/kWh]

$C_{e} \quad$ Electricity tariff

$[£ 0.01 / \mathrm{kWh}]$

$C_{e x}$

Electricity export tariff

[£0.01/kWh]

$D_{h}$

Hydraulic Diameter

[m]

$D R_{2} \quad$ Diffusion Ratio, $\frac{W_{1 s}}{W_{2}}$

$\Delta \mathrm{H} \quad$ Total enthalpy rise across compressor

$[\mathrm{kJ} / \mathrm{kg}]$

$\eta_{b} \quad$ Burner efficiency

$\eta_{c} \quad$ Compressor efficiency, $\frac{\left(T_{02 s}-T_{01}\right)}{\left(T_{02}-T_{01}\right)}$

$\eta_{C B}$

Condensing boiler efficiency

$\eta_{G E N}$

DCHP Generator efficiency, $\frac{W_{D}}{W_{n e t}}$

$\eta_{H E X} \quad$ Heat exchanger effectiveness, $\frac{\left(T_{05}-T_{02}\right)}{\left(T_{04}-T_{02}\right)}$ (MGT)

$$
\frac{Q_{D}}{Q_{\text {out }}}(\mathrm{DCHP})
$$

$\eta_{m} \quad$ Mechanical efficiency, $\frac{W_{\text {in }}}{W_{\text {out }}}$

$\eta_{s} \quad$ Gas turbine thermal efficiency, $\frac{\eta_{b} W_{n e t}}{Q_{i n}}$

$\eta_{t} \quad$ Turbine efficiency, $\frac{\left(T_{03}-T_{04}\right)}{\left(T_{03}-T_{04 s}\right)}$

$E_{g} \quad \mathrm{CO}_{2}$ Gas emission factor

$[\mathrm{kg} / \mathrm{kWh}]$

$E_{e} \quad \mathrm{CO}_{2}$ Electricity emission factor

$[\mathrm{kg} / \mathrm{kWh}]$

$E_{e x} \quad \mathrm{CO}_{2}$ Electricity export emission factor

$[\mathrm{kg} / \mathrm{kWh}]$

$N$

Shaft speed

[rev/min] 
$N_{s} \quad$ Specific Speed, $\frac{\omega \sqrt{\left(\dot{m} / \rho_{0 \text { avg }}\right)}}{\Delta H^{3 / 4}}$

$\dot{m} \quad$ Mass flow

$[\mathrm{kg} / \mathrm{s}]$

Pressure drop ratio, $\frac{\left(1-\frac{\Delta P_{h a}}{P_{02}}-\frac{\Delta P_{b}}{P_{02}}\right)}{\left(1+\frac{\Delta P_{h g}}{P_{01}}\right)}$

$P_{01} \quad$ Compressor inlet total pressure

[bar]

$P_{02} \quad$ Compressor exit total pressure

[bar]

$\frac{\Delta P_{b}}{P_{02}} \quad$ Burner pressure drop

$\frac{\Delta P_{h a}}{P_{02}} \quad$ Heat exchanger air side pressure drop

$\frac{\Delta P_{h g}}{P_{01}} \quad$ Heat exchanger gas side pressure drop

$Q_{R} \quad$ Required thermal energy (by user)

[kW]

$Q_{D} \quad$ Delivered thermal energy (from DCHP)

$Q_{\text {in }} \quad$ Gas turbine thermal power input

$Q_{\text {out }} \quad$ Gas turbine thermal energy output, $Q_{i n}-W_{\text {net }}$

$[\mathrm{kW}]$

$r_{c} \quad$ Pressure ratio, $\frac{P_{O 2}}{P_{O 1}}$

$r_{c}{ }^{\prime} \quad$ Pressure ratio, $\frac{P_{O 2}}{P_{O 1}}$, for optimum system efficiency

$\operatorname{Re} \quad$ Reynolds number, $\operatorname{Re}=\frac{W_{\text {avg }} D_{h}}{v_{\text {avg }}}$

$r_{2} \quad$ Impeller exit radius

$r_{1 h} \quad$ Impeller inlet hub radius

$r_{1 s} \quad$ Impeller inlet shroud radius

$T_{O 1} \quad$ Compressor inlet total temperature

$T_{1} \quad$ Impeller inlet static temperature

$T_{O 2} \quad$ Compressor exit total temperature 
$T_{2 p} \quad$ Impeller exit static temperature

$T_{O 3} \quad$ Turbine inlet total temperature (TIT)

$T_{O 4} \quad$ Turbine exit temperature

$T_{O 5} \quad$ Recuperator inlet total temperature

$U_{2} \quad$ Impeller exit blade speed

$v_{\text {avg }}$

Average dynamic viscosity across impeller

$\omega$

Shaft speed

Average relative impeller speed, $\frac{\left(W_{2}+W_{1}\right)}{2}$

$W_{1} \quad$ Impeller inlet relative flow speed (mean)

$W_{1 s} \quad$ Impeller inlet relative flow velocity (shroud)

$W_{2}$ Impeller tip relative flow velocity

Net electrical power from gas turbine, $W_{\text {out }}-W_{\text {in }}$

$W_{R} \quad$ Required electrical power (by user)

$W_{D} \quad$ Delivered electrical power (from DCHP)

Exported electrical power, $W_{D}-W_{R}$

\section{Acronyms}

$\begin{array}{ll}\text { BOP } & \text { Best Operating Point } \\ \text { CFD } & \text { Computational Fluid Dynamics } \\ \text { DCHP } & \text { Domestic Combined Heat and Power } \\ \text { MGT } & \text { Micro Gas Turbine } \\ \text { MWhe } & \text { Mega Watt hours electrical } \\ \text { MWht } & \text { Mega Watt hours thermal } \\ \text { PS } & \text { Pressure Side } \\ \text { SS } & \text { Suction Side }\end{array}$




\section{REFERENCES}

1. Clay, A. and G.D. Tansley, An Analysis of Micro Gas Turbines for UK Domestic Combined Heat and Power. Power Engineer, 2010. 14(3).

2. WhisperGen. 2007 [cited 2010 5th March]; Available from: http://www.whispergen.com/main/HOME/.

3. Baxi. Baxi Ecogen. 2009 [cited 2010 5th March]; Available from: http://www.baxi.co.uk/docs/Baxi microchp leaflet.pdf.

4. CarbonTrust. Micro CHP Accelerator Interim Report. The Carbon Trust Publications 2007 [cited 2010 5th March]; Available from: http://www.carbontrust.co.uk/publications/publicationdetail?productid=CTC726.

5. $\quad$ Peirs, J., Waumans, J., Vleugels, P., Al-Bender, F., Stevens, T., Verstaete, T., Stevens, S., D'hulst, R., Vertraete, D., Fiorini, P., Van den Brambussche, R., Driesen, J., Puers., Hendrick, P., Baelmans, M., Reynarts, D., Micropower generation with microgasturbines: a challenge. Proceedings of the Institution of Mechanical Engineers, Part C: Journal of Mechanical Engineering Science, 2007. 221(4): p. 489-500.

6. MiTi, Low-Friction, Wear-Resistant Korolon Coatings for High-Temperature, High-Speed, Air Foil Bearings. Mohawk Innovative Technology Inc. Development Newsletter, 2005. 23: p. 4.

7. Pampreen, R., C., Small turbomachinery compressor and fan aerodynamics. ASME Journal of Engineering Power, 1973. 95.

8. Hodge, J., Cycles and Performance Estimation. 1st ed. Gas turbine series; vol 1. 1955: Butterworth's Scientific Publications. 329.

9. Japikse, D., Introduction to Turbomachinery. 2nd ed. 1997, Vermont \& Oxford: Concepts ETI. Inc \& Oxford Univerisity Press.

10. Shepherd, D.G., Principles of Turbomachinery. 1956, New York: The Macmillan Company.

11. Flaxington, D. and E. Swain, Turbocharger aerodynamic design. Proceedings of the Institution of Mechanical Engineers, Part C: Journal of Mechanical Engineering Science, 1999. 213: $p$. 14.

12. Japikse, D., Centrifugal Compressor Design and Performance. 1996, Vermont: Concepts ETI, Inc.

13. Whitfield, A. and N.C. Bains, Design of Radial Turbomachines. 1990, Harlow: Longman Scientific \& Technical. 397.

14. Hildebrandt, A. and M. Genrup, Numerical Investigation of the Effect of Different Back Sweep Angle and Exducer Width on the Impellor Outlet Flow Pattern of a Centrifugal Compressor With Vaneless Diffuser. Journal of Turbomachinery, 2007. 129: p. 12.

15. Van Den Braembussche, R.A. Micro Gas Turbines - A Short Survey of Design Problems. In Micro Gas Turbines, Educational Notes RTO-EN-AVT-131. In Micro Gas Turbines (1-1 - 1-18) 2005 [cited 2010 5th March]; Available from: http://www.rta.nato.int/pubs/rdp.asp?RDP=RTOEN-AVT-131.

16. Rodgers, C. Specific speed and efficiency of centrifugal impellers. in Performance prediction of centrifugal pumps and compressors; Proceedings of the Twenty-fifth Annual International Gas Turbine Conference and Exhibit and Twenty-second Annual Fluids Engineering Conference. . 1980. New Orleans: American Society of Mechanical Engineers.

17. FLUENT, Ansys Fluent 12.0 User's Guide 2009: ANSYS Inc.

18. Verstraete, T., Z. Alsalihi, and R.A. Van den Braembussche, Numerical study of the heat transfer in micro gas turbines. Journal of turbomachinery, 2007. 129(4): p. 835-841.

19. Boyce, M.P., The gas turbine engineering handbook. 3rd rev. ed. ed. 2006, Boston; Oxford: Gulf Publishing.

20. Flaxington, D. and B. Mahbod. Turbocharger compressor developmens for broad range and high pressure ratio applications. in 4th International conference on turbocharging and turbomachinary 1990: IMECHE.

21. Tang, J., Computational analysis and optimization of real gas flow in small centrifugal compressors, in Department of Energy and Environmental Technology. 2006, Lappeenranta University of Technology: Lappeenranta. p. 97.

22. Isomura, K., Murayama, M., Teramoto, S., Hikichi, K., Endo, Y., Togo, S., Tanaka, S., Experimental verification of the feasibility of a $100 \mathrm{~W}$ class micro-scale gas turbine at an impeller diameter of $10 \mathrm{~mm}$. Journal of Micromechanics and Microengineering, 2006(9): $\mathrm{p}$. S254.

23. Saravanamutto, H., G.F.C. Rogers, and H. Cohen, Gas Turbine Theory. 5th ed. 2001, Harlow: Pearson Education Limited. 491. 
24. Casey, M.V., A computational Geometry for the Blades and Internal Flow Channels of Centrifugal Compressors. Transactions - American Society of Mechanical Engineers Journal of Engineering for Power, 1981. 82-GT-155: p. 1-10.

25. Wang, W., R. Cai, and N. Zhang, General characteristics of single shaft microturbine set at variable speed operation and its optimization. Applied Thermal Engineering, 2004. 24(13): p. $1851-1863$.

26. Newborough, M., Assessing the benefits of implementing micro-CHP systems in the UK. Proceedings of the I MECH E Part A Journal of Power and Energy, 2004. 218: p. 203-218.

27. Costyn, J. Micro CHP Policy Overview. in CHPA Annual Conference. 2009. London, England: CHPA. 